\title{
Metal Complexes of quinolin-8-yl (1, 3-benzoxazol-2-ylsulfanyl) acetate: Spectral, XRD, thermal, molecular docking and biological evaluation
}

\author{
Naveen Aradhya S.V. ${ }^{1}$, Vishnumurthy K. A. ${ }^{1 *}$, H.S. Bhojya Naik ${ }^{2}$, \\ Manjuraj. $\mathrm{T}^{3}$, Jayanna $\mathrm{N} \mathrm{D}^{3}$ \\ ${ }^{I}$ Department of PG studies in Industrial chemistry, Sir M.V Govt Science College, Bhadravathi. Karnataka \\ (INDIA) \\ ${ }^{2}$ Department of Post graduation studies in Industrial Chemistry, jnana sahyadri, Kuvempu University, \\ Shankaraghatta, Karnataka INDIA. \\ ${ }^{3}$ Department of Chemistry, Sahyadri Science College (Auto), Shimoga, Karnataka (INDIA). \\ Corresponding author: vishnumurthy.ka11@gmail.com
}

\begin{abstract}
The series of $\mathrm{Co}(\mathrm{II}), \mathrm{Ni}$ (II) and $\mathrm{Cu}(\mathrm{II})$ metal complexes quinolin-8-yl (1,3-benzoxazol-2ylsulfanyl)acetate (BZ) have been synthesized. All the complexes thoroughly characterized by different physicochemical and spectroscopic techniques (UV-Vis, IR, NMR and ESI-Mass). The powder XRD indicates the crystalline state and morphology of $\mathrm{Ni}$ (II) and $\mathrm{Cu}$ (II) metal complexes, the thermal stability of the metal complexes as been performed. In the current study, the synthesized compounds were evaluated for their antioxidant activity by using DPPH assay, $\mathrm{Cu}$ (II) metal complex exhibited higher antioxidant activity almost close to the standard BHT. In addition, antioxidant activity is correlated with docking interactions of human antioxidant enzyme receptor with the competitive inhibitor DTT (PDB: $3 M N G)$, which showed greater binding interactions with metal complexes. The antimicrobial studies has been carried out against different bacterial and fungal strains and the results showed that metal complexes be more active than the ligand BZ.
\end{abstract}

Keywords; Benzoxazole, metal complex, XRD, Antioxidant, molecular docking.

\section{Introduction}

The benzoxazole and its derivatives are known to play exceptionally vital roles in medicinal chemistry which finds use as a preliminary material for the synthesis of larger nucleus. a range of benzoxazole derivatives were extensively considered for their biological and pharmacological activities concerning antibiotic [1,2] antimicrobial [3-5] antifungal [6-8] and antitumor activities [9-11]. In addition, benzoxazole analogous and their metallic complexes have been widely applied for use in chemistry and medicine with various transition metal ions via nitrogen donor atoms [12-14]. Better antimicrobial and antitumor activities have been reported for a few metal-benzoxazole complexes [15-17] in comparison with isolated benzoxazole ligands.

Keeping in view of this we hereby report the synthesis of ligand quinolin-8-yl (1,3-benzoxazol-2ylsulfanyl)acetate (BZ) and their characterization by elemental, spectral and XRD analysis were performed. We aimed to evaluate the antioxidant features of metal complexes, In-vivo and docking interactions. In-vitro and Antimicrobial activity of ligand (BZ) and metal complexes were also performed against bacterial and fungal strains.

\subsection{Materials}

\section{Experimental Section}

The chemicals 5-chloro-2mercapto-benzoxazole and 8-Quinolinol were Sigma-Aldrich Co. The chlorides of $\mathrm{Co}(\mathrm{II}), \mathrm{Ni}(\mathrm{II})$ and $\mathrm{Cu}(\mathrm{II})$ were of S.R.L. grade. All other reagents and solvents were purchased from commercial sources and were of analytical grade

\subsection{Physical measurements}

Melting points had been recorded on an electro-thermal melting factor apparatus and are uncorrected. ${ }^{1} \mathrm{H}$ NMR spectra were recorded on Bruker $400 \mathrm{MHz}$ spectrometer at IISc, Bangalore, Karnataka, India. The chemical shifts have been proven in $\delta$ values (ppm) with tetramethylsilane(TMS) as an internal standard. LCMS changed into acquired the usage of a C-18 column on Shimadzu, LCMS 2010A, Japan. The FT-IR spectra of the compounds were taken as $\mathrm{KBr}$ pellet (a $100 \mathrm{mg}$ ) the usage of Shimadzu Fourier Transform Infrared (FTIR) spectrometer. Magnetic susceptibility have been measured at $35{ }^{\circ} \mathrm{C}$ through the Gouy technique, Silica gel GF254 thin plates from Merck were used for TLC and spots were positioned either by UV or dipping in potassium permanganate solution. The powder X-ray studies was carried out by using Rigaku MiniFlex 
Metal Complexes of quinolin-8-yl (1, 3-benzoxazol-2-ylsulfanyl) acetate: Spectral, XRD, thermal,

instrument with $\mathrm{Cu}-\mathrm{K}_{\alpha}$ radiation (wavelength $0.154 \mathrm{~nm}$ ) and The thermal gravimetric analysis of all metal complexes were taken by the Diamond TG/DT Analyzer (TG/DTA) at room temperature of $700^{\circ} \mathrm{C}$ below heating pace of $20^{\circ} \mathrm{C} \mathrm{min}^{-1}$.

\subsection{Synthesis of Ligand and Complexes}

\section{Synthesis of quinolin-8-yl (1,3-benzoxazol-2-ylsulfanyl)acetate (BZ)}

Step-1

The 8-hydroxyquinoline $(5.0 \mathrm{mmol})$ is dissolved in the mixture of Tetra hydrfuran and Try ethylamine, stirred at room temperature by adding chloroacetyl chloride drop wise and the reaction mixture stirred for $8 \mathrm{~h}$ the product formed was filtrated. The solvent was removed under vacuum and washed with Hot ethanol and dried over anhydrous $\mathrm{Na}_{2} \mathrm{SO}_{4}$ and the product was obtained as cream solid. Yield: $75 \%$. m.p. $160-162{ }^{\circ} \mathrm{C}$.

Step-2

A mixture 2-mercaptobenzoxazole $(4.2 \mathrm{mmol})$ and quinolin-8-yl chloroacetate $(4.2 \mathrm{mmol})$ dissolved in anhydrous ethanol $(30 \mathrm{~mL})$ The mixture was heated under reflux for $12 \mathrm{~h}$, the reaction mixture poured into cursed ice and the precipitate was collected by filtration and washed with ethanol, the product was obtained as cream color.

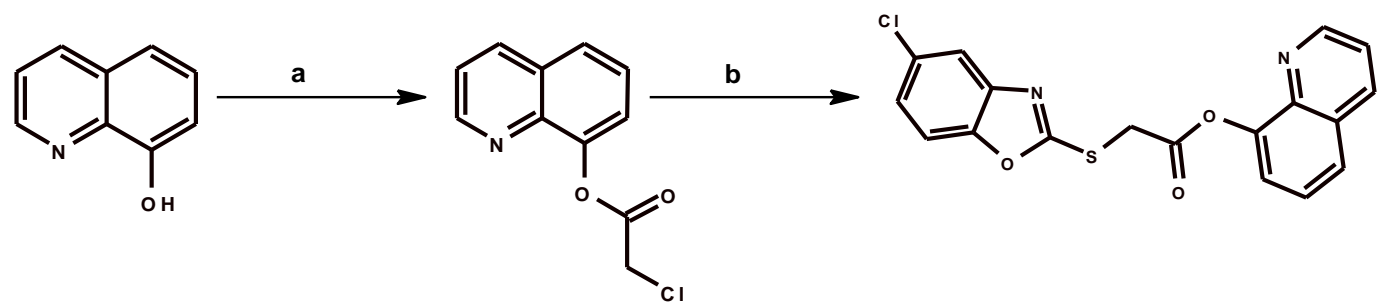

Scheme 1 [a] THF, TEA RT, 8h [b] 2-mercaptobenzoxazole, Dry $\mathrm{C}_{2} \mathrm{H}_{5} \mathrm{OH}$

\subsection{Synthesis of metal complexes}

The Ethanolic solution of metal (II) chlorides $(0.02 \mathrm{~mol})$ was added in drops of ethanolic of ligand BZ $(0.04 \mathrm{~mol})$ and the mixture was refluxed on water bath at $70{ }^{\circ} \mathrm{C}$ for $4-5 \mathrm{~h}$. The solid complex obtained was filtered, washed with hot ethanol and dried in vacuum over anhydrous calcium chloride.

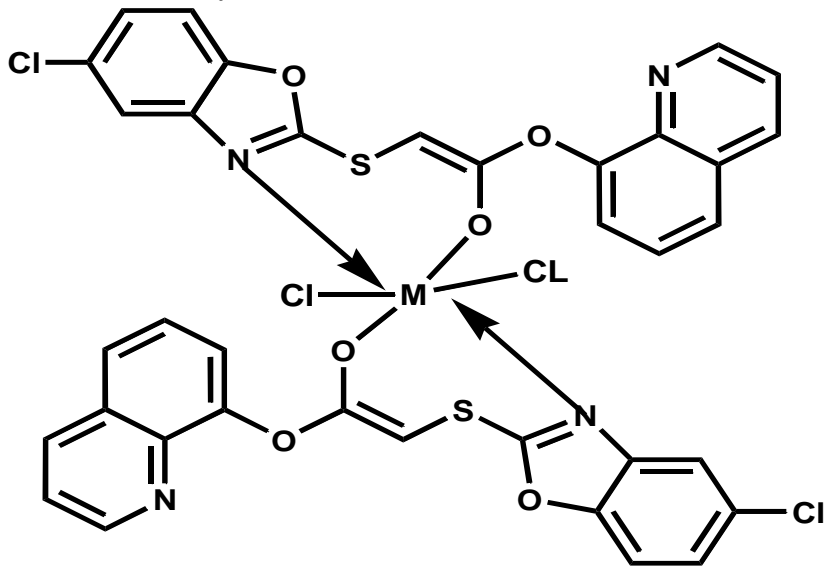

Figure 1 Proposed structures of Metal complexes $(\mathrm{M}=\mathrm{Co}, \mathrm{Ni}, \& \mathrm{Cu})$

\subsection{Antioxidant activity}

\section{Biological activity}

The free radical scavenging activity of the ligand BI and complexes was measured In vitro by 2, 20diphenyl-1-picrylhydrazyl (DPPH) assay. The stock solution was prepared by dissolving $24 \mathrm{mg}$ DPPH with 100 $\mathrm{ml}$ methanol and stored at $20^{\circ} \mathrm{C}$ until required. The working solution was obtained by diluting DPPH solution with methanol to attain an absorbance of about $0.98 \pm 0.02$ at $517 \mathrm{~nm}$ using the spectrophotometer All the tested samples in various concentrations $(50,75$ and $100 \mu \mathrm{g} / \mathrm{mL})$ were prepared in methanol and the homogeneous solutions were achieved by stirring. A liquot of test sample $(1 \mathrm{~mL})$ was added to $4 \mathrm{~mL}$ of $0.004 \%$ (w/v) methanol solution of DPPH and then reaction mixture was vortexed for 1 min and kept at room temperature for $30 \mathrm{~min}$ in the dark to complete the reaction. The absorbance was read against blank at $517 \mathrm{~nm}$. The synthetic antioxidant BHT was used as positive control $[18,19]$. The ability of the tested samples at tested concentration to scavenge DPPH radicals was calculated using equation.

Scavenging ratio $(\%)=\left[\left(A_{i}-A_{o}\right) /\left(A_{c}-A_{o}\right)\right] \times 100 \%$ 
Metal Complexes of quinolin-8-yl (1, 3-benzoxazol-2-ylsulfanyl) acetate: Spectral, XRD, thermal,

Where $A_{i}$ is the absorbance in the presence of the test compound; $A_{0}$ is absorbance of the blank in the absence of the test compound; $\mathrm{A}_{\mathrm{c}}$ is the absorbance in the absence of the test compound.

\subsection{Molecular docking}

Molecular modeling studies were performed by using Hex 8.0.0 protein-ligand docking in PDB formats. The parameters used for docking include: correlation type-shape only, FFT mode -3D, grid dimension -0.6 , receptor range -180 , ligand range -180 , twist range -360 , distance range -40 . The starting coordinates of the human antioxidant enzyme in complexes with the competitive inhibitor DTT (PDB: $3 M N G)$ were taken from the Protein Data Bank (http://www.rcsb.org/pdb) $[18,20]$. The selected ligands were docked against the lead competitive inhibitor ligand DTT at the crystal enzyme structure of the target protein and the best energy conformations of receptor ligand were studied, and the energy of binding was calculated as the difference between the energy of the complex and the individual energies of enzyme and ligand.

\section{Results and Discussion}

The analytical data of the metal complexes reveals that while reactions with metal (II) chlorides and ligand performed in 1:2 (M:L) molar ratio, the BZ behaves as a bidentate ligand and coordinate through metal oxazole nitrogen and metal oxygen of carbonyl group giving octahedral geometry for $\mathrm{Co}(\mathrm{II}), \mathrm{Ni}$ (II) and $\mathrm{Cu}$ (II) complexes. The observed molar conductance of the complexes in DMSO $\left(10^{-2} \mathrm{M}\right.$ solution) are consistent with $\mathrm{Co}(\mathrm{II}), \mathrm{Ni}(\mathrm{II})$ and $\mathrm{Cu}(\mathrm{II})$ complexes are non electrolytic in nature [21].

Table 1 Analytical data and molar conductance data BZ and metal complexes

\begin{tabular}{|c|c|c|c|c|c|c|c|c|}
\hline \multirow[t]{2}{*}{ Compounds } & \multirow[t]{2}{*}{ Colour } & \multirow[t]{2}{*}{ Mol.Wt } & \multirow{2}{*}{$\begin{array}{l}\text { Yield } \\
(\%)\end{array}$} & \multicolumn{3}{|c|}{ Calcd. (found) (\%) } & \multirow{2}{*}{$\begin{array}{c}\text { Molar conductance } \\
\left(\mathrm{ohm}^{-1}\right. \\
\left.\mathrm{cm}^{2} \mathrm{~mol}^{-1}\right)\end{array}$} & \multirow{2}{*}{$\begin{array}{l}\text { Melting } \\
\text { point }^{\circ} \mathrm{C}\end{array}$} \\
\hline & & & & $C$ & $\boldsymbol{H}$ & $N$ & & \\
\hline $\mathbf{B Z}$ & Pale Yellow & 739.60 & 79 & $58.46(58.04)$ & $2.73(2.14)$ & $7.58(6.95)$ & - & 180 \\
\hline$\left[\mathrm{Co}(\mathrm{BZ})_{2} \mathrm{Cl}_{2}\right] .2 \mathrm{H}_{2} \mathrm{O}$ & Light blue & 866.89 & 65 & $49.73(48.93)$ & $2.32(2.01)$ & $6.78(6.14)$ & 38.12 & $>250$ \\
\hline$\left[\mathrm{Ni}(\mathrm{BZ})_{2} \mathrm{Cl}_{2}\right] . \mathrm{H}_{2} \mathrm{O}$ & Pale green & 865.89 & 69 & $49.75(49.12)$ & $2.32(2.01)$ & $6.45(6.09)$ & 35.2 & $>250$ \\
\hline$\left[\mathrm{Cu}(\mathrm{BZ})_{2} \mathrm{Cl}_{2}\right] .2 \mathrm{H}_{2} \mathrm{O}$ & dark blue & 870.89 & 74 & $49.47(49.14)$ & $2.31(2.01)$ & $7.27(6.98)$ & 27.5 & $>250$ \\
\hline
\end{tabular}

\section{1. ${ }^{1} \mathrm{H}$ NMR and Mass spectra}

NMR spectra of ligand BZ showed singlet peak appears at $4.94 \mathrm{ppm}$ attributed to $-\mathrm{CH}_{2}$ protons, The multiple signals at 7.88 to $7.06 \mathrm{ppm}$ attributed to aromatic protons of 8-hydroxyquinoline and 2mercaptobenzoxazole rings respectively which reveals the structural evidences for BZ (Figure 2). In the mass spectra pattern (Figure 3) showed molecular ion peak $\left[\mathrm{M}^{+}\right]$at $\mathrm{m} / \mathrm{z} 336.1$ (335.4), that concurrence with the molecular weight of BZ ligand respectively.

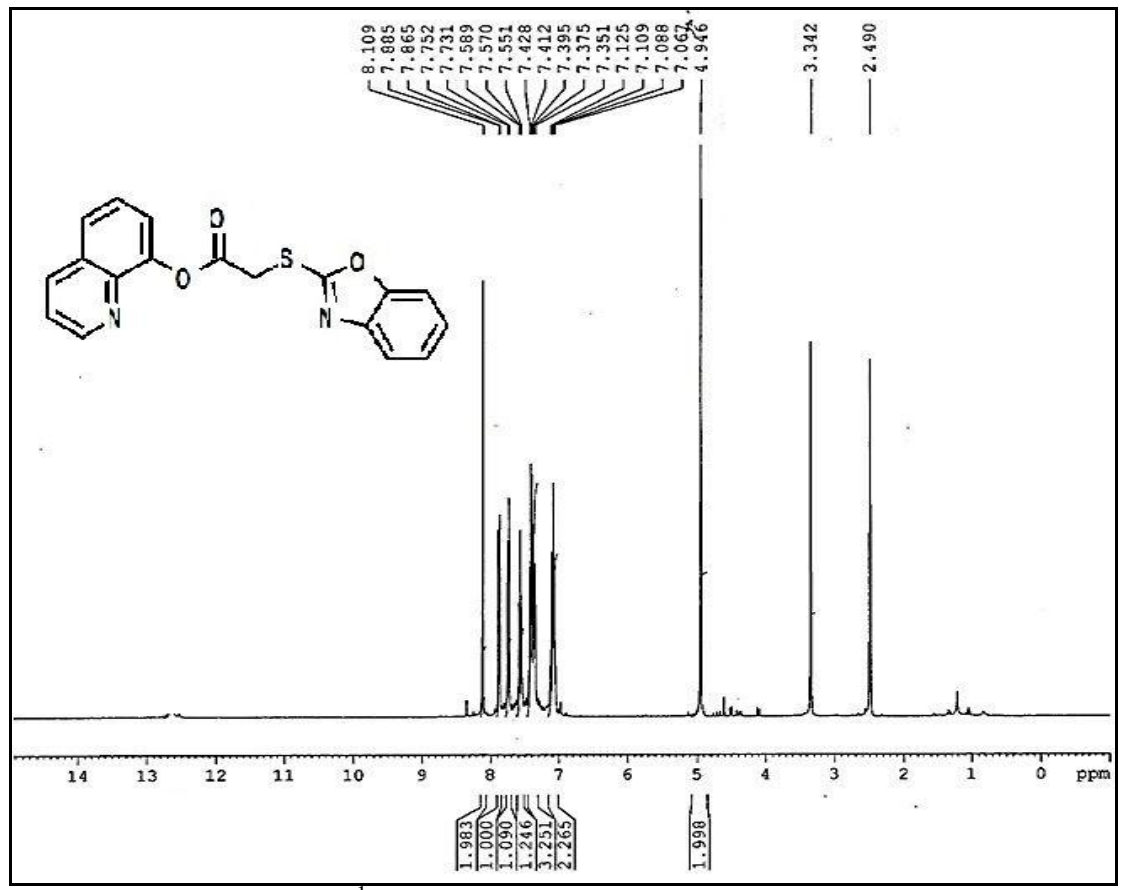

Fig.2 ${ }^{1} \mathrm{H}$ NMR spectrum of the ligand BZ 
Metal Complexes of quinolin-8-yl (1, 3-benzoxazol-2-ylsulfanyl) acetate: Spectral, XRD, thermal,

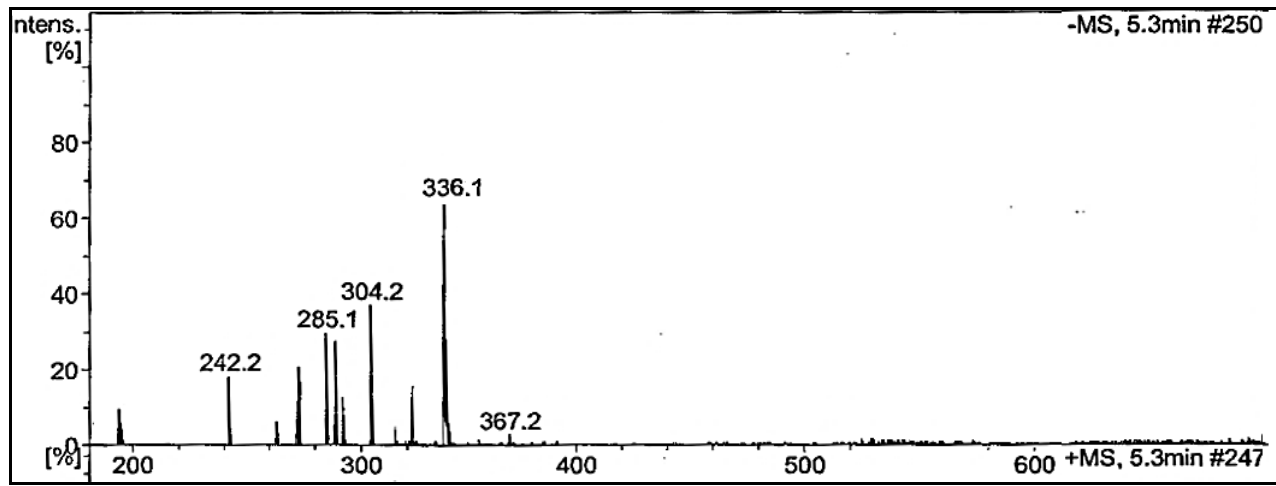

Fig.3 Mass spectrum of the ligand BZ

\subsection{IR spectra}

The IR spectra of the ligand shows the sharp peak at $1696 \mathrm{~cm}^{-1}$ for $\mathrm{C}=\mathrm{O}$ group, while in the Coordinated metal complexes the $\mathrm{C}=\mathrm{O}$ group is shifted to a lower frequency of $1605 \mathrm{~cm}^{-1}, 1604 \mathrm{~cm}^{-1}$ and $1612 \mathrm{~cm}^{-1}$ in its $\mathrm{Co}(\mathrm{II}), \mathrm{Ni}(\mathrm{II})$ and $\mathrm{Cu}(\mathrm{II})$ complexes indicating coordination of the $\mathrm{C}=\mathrm{O}$ group to the metal ion [22]. Followed by $-\mathrm{C}=\mathrm{N}$ group shows band at $1604 \mathrm{~cm}^{-1}$ for ligand and it was shifted to lower frequency of $40-$ $50 \mathrm{~cm}^{-1}$ in the metal complexes suggesting that coordination through $-\mathrm{C}=\mathrm{N}$ group. The medium band appears at $1103 \mathrm{~cm}^{-1}$ for $\mathrm{C}-\mathrm{O}$ stretching, and $704 \mathrm{~cm}^{-1}$ for $\mathrm{C}-\mathrm{Cl}$ group in free ligand. Coordination properties of the ligand and suggesting the association of oxygen atoms in the bonding with the metal ions observed at the range of 520 $\mathrm{cm}^{-1}, 528 \mathrm{~cm}^{-1}$ and $530 \mathrm{~cm}^{-1}$, for $v(\mathrm{M}-\mathrm{O})$ bonding and followed $467 \mathrm{~cm}^{-1}, 465 \mathrm{~cm}^{-1}$ and $470 \mathrm{~cm}^{-1}$ are assigned as $v(\mathrm{M}-\mathrm{N})$ bonding [23.24] .

\subsection{Electronic spectra and magnetic moments}

The electronic spectral data of ligand shows two strong peaks at 44,843 and $38,023 \mathrm{~cm}^{-1}$ attributed to the presence of $\pi-\pi^{*}$ and $n-\pi^{*}$ transitions [25]. The $\pi-\pi^{*}$ transition in the complexes $\left(\mathrm{Co}^{\mathrm{II}}, \mathrm{Ni}^{\mathrm{II}}, \mathrm{Cu}^{\mathrm{II}} \& \mathrm{Zn}^{\mathrm{II}}\right)$ is shifted to a longer wavelength as a consequence of coordination to the metal-ligand. The Co(II) complex exhibits three spin allowed transitions at 19555, 14728 and $9546 \mathrm{~cm}^{-1}$ assignable to ${ }^{4} \mathrm{~T}_{1 \mathrm{~g}}(\mathrm{~F}) \rightarrow{ }^{4} \mathrm{~T}_{1 \mathrm{~g}}(\mathrm{P})$, ${ }^{4} \mathrm{~T}_{1 \mathrm{~g}}(\mathrm{~F}) \rightarrow{ }^{4} \mathrm{~A}_{2 \mathrm{~g}}(\mathrm{~F})$ and ${ }^{4} \mathrm{~T}_{1 \mathrm{~g}}(\mathrm{~F}) \rightarrow{ }^{4} \mathrm{~T}_{2 \mathrm{~g}}(\mathrm{~F})$ transitions respectively, It has a magnetic susceptibility value of $5.02 \mathrm{BM}$ suggest an octahedral geometry for $\mathrm{Co}^{\text {II }}$ complex [26], $\mathrm{Ni}$ (II) complex exhibits two absorptions bands at 24,507 and $18,182 \mathrm{~cm}^{-1}$ assignable to ${ }^{3} \mathrm{~A}_{2 \mathrm{~g}}(\mathrm{~F}) \rightarrow{ }^{3} \mathrm{~T}_{1 \mathrm{~g}}(\mathrm{P})$ and ${ }^{3} \mathrm{~A}_{2 \mathrm{~g}}(\mathrm{~F}) \rightarrow{ }^{3} \mathrm{~T}_{1 \mathrm{~g}}(\mathrm{~F})$ transitions respectively, exhibiting the magnetic moment of $3.12 \mathrm{BM}$, representing octahedral geometry. The absorption spectrum of $\mathrm{Cu}$ (II) complex has one broad band at $26,876 \mathrm{~cm}^{-1}$, assigned to ${ }^{2} \mathrm{~B}_{1 \mathrm{~g}} \rightarrow{ }^{2} \mathrm{E}_{1 \mathrm{~g}}$ transition. The observed magnetic moment of the $\mathrm{Cu}$ (II) complex is 2.17 B.M., which confirms the octahedral structure of this complex [27].

\subsection{XRD analysis}

The powder XRD diffraction is carried out for $\mathrm{Ni}(\mathrm{II})$ and $\mathrm{Cu}(\mathrm{II})$ complexes which shows prominent sharp peaks while no peaks for the rest of the complexes indicating that their amorphous in nature, by evaluating the diffraction patterns of complexes given in figure 2 which reveals Crystalline nature of the complexes [28 29].
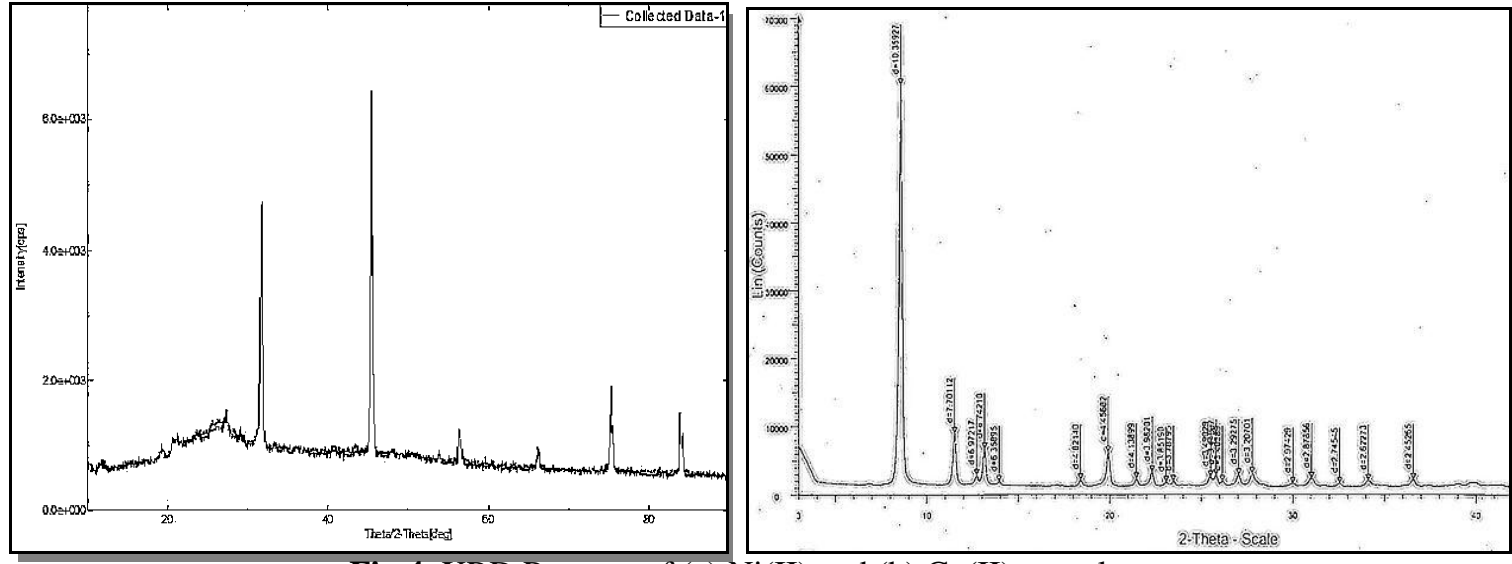

Fig 4. XRD Patterns of (a) $\mathrm{Ni}(\mathrm{II})$ and (b) $\mathrm{Cu}(\mathrm{II})$ complexes

The Miller indices $(h k l)$ along with observed and calculated $d$ angles, $2 \theta$ values, and relative intensities are given in Tables 2 and 3. The average crystallite sizes of the complexes dxrd were calculated using Debye Scherrer equation $(\mathrm{D}=\mathrm{K} \lambda / \beta \operatorname{Cos} \theta)$ Where $\mathrm{D}=$ Particle size, $\mathrm{K}=$ Dimensionless shape factor, $\lambda=$ Xray 
Metal Complexes of quinolin-8-yl (1, 3-benzoxazol-2-ylsulfanyl) acetate: Spectral, XRD, thermal,

wavelength $(0.15406 \AA) \beta=$ Line broadening at half the maximum intensity, $\theta=$ Diffraction angle. Complexes 1 and 3 have a crystallite size of 30.45 and $35.21 \mathrm{~nm}$ respectively suggesting that the complexes are in a nanocrystalline phase.

Table 2. XRD data of [Ni (II)] complex

\begin{tabular}{|c|c|c|c|c|c|c|c|c|}
\hline \multirow{2}{*}{ Peak No } & \multirow{2}{*}{$2 \theta$} & \multirow{2}{*}{$\boldsymbol{\theta}$} & \multirow{2}{*}{$\operatorname{Sin} \theta$} & \multirow{2}{*}{ h k l } & \multicolumn{2}{|c|}{ D } & \multirow{2}{*}{ Intensity } & \multirow{2}{*}{ a in $\AA$} \\
\hline & & & & & Cal & obs & & \\
\hline 1 & 8.529 & 4.264 & 0.0743 & 110 & 10.36 & 10.359 & 100 & 5.65 \\
\hline 2 & 11.481 & 5.740 & 0.1000 & 445 & 7.70 & 7.701 & 14.8 & 5.65 \\
\hline 4 & 12.686 & 6.343 & 0.1104 & 396 & 6.97 & 6.972 & 4.5 & 5.65 \\
\hline 5 & 13.915 & 6.95 & 0.1210 & 414 & 6.36 & 6.742 & 3.0 & 5.65 \\
\hline 6 & 18.387 & 9.193 & 0.1597 & 461 & 4.82 & 4.821 & 3.4 & 5.65 \\
\hline 7 & 19.09 & 9.545 & 0.1658 & 566 & 4.64 & 4.456 & 10.2 & 5.65 \\
\hline 8 & 21.452 & 10.726 & 0.1861 & 635 & 4.13 & 4.38 & 5.4 & 5.65 \\
\hline 9 & 22.308 & 11.25 & 0.1951 & 630 & 3.94 & 3.982 & 2.9 & 5.65 \\
\hline 10 & 23.071 & 11.535 & 0.1999 & 670 & 3.85 & 3.878 & 3.1 & 5.65 \\
\hline 11 & 25.500 & 12.75 & 0.2206 & 832 & 3.49 & 3.409 & 4.2 & 5.65 \\
\hline
\end{tabular}

Table 3 XRD data of [Cu (II)] complex

\begin{tabular}{|c|c|c|c|c|c|c|c|c|}
\hline \multirow[b]{2}{*}{ Peak No } & \multirow[b]{2}{*}{$2 \theta$} & \multirow[b]{2}{*}{$\boldsymbol{\theta}$} & \multirow[b]{2}{*}{$\operatorname{Sin} \theta$} & \multirow[b]{2}{*}{ h k l } & \multicolumn{2}{|c|}{ D } & \multirow[b]{2}{*}{ Intensity } & \multirow[b]{2}{*}{$\mathrm{a}$ in $\AA$} \\
\hline & & & & & Cal & obs & & \\
\hline 1 & 20.7275 & 10.36375 & 0.1798 & 635 & 4.2818 & 4.2825 & 13.3103 & 3.62 \\
\hline 2 & 27.2962 & 13.6481 & 0.2359 & 829 & 3.2645 & 3.264 & 15.7031 & 3.62 \\
\hline 4 & 31.6896 & 15.8448 & 0.2730 & 926 & 2.8212 & 2.820 & 67.3941 & 3.62 \\
\hline 5 & 31.8186 & 15.9093 & 0.2741 & 837 & 2.8101 & 2.8091 & 33.7029 & 3.62 \\
\hline 6 & 45.4042 & 22.7021 & 0.3859 & 428 & 1.9950 & 1.9953 & 84.6667 & 3.62 \\
\hline 7 & 45.6651 & 22.83255 & 0.3880 & 435 & 1.9851 & 1.9845 & 34.6159 & 3.62 \\
\hline 8 & 56.344 & 28.172 & 0.4721 & 454 & 1.6315 & 1.6310 & 27.3827 & 3.62 \\
\hline 9 & 66.1056 & 33.0528 & 0.5453 & 365 & 1.4123 & 1.4128 & 23.7947 & 3.62 \\
\hline 10 & 75.3033 & 37.65165 & 0.6108 & 398 & 1.2612 & 1.2606 & 43.1507 & 3.62 \\
\hline 11 & 83.9143 & 41.95715 & 0.6685 & 352 & 1.1521 & 1.1518 & 39.954 & 3.62 \\
\hline
\end{tabular}

\subsection{Thermal Analysis}

The TGA curves of the metal complexes are presented in figure. The Co (II) complexes were having three stages of decomposition, in which first stage involves in the Co (II) complex shows a mass loss of $7.5 \%$ (calcd.8.2\%) in the temperature range $80-95{ }^{\circ} \mathrm{C}$ indicates the loss of two lattice water molecules. The second step of the decomposition from $210-320{ }^{\circ} \mathrm{C}$, with a mass loss of $38.0 \%$ (calcd. $40.58 \%$ ) corresponds to the decomposition of the coordinated part of the oxazole moiety in the ligand, the third step involves in the dissociation at the temperature of $340-550{ }^{\circ} \mathrm{C}$ with weight loss of $42.0 \%$ (calcd. $44.18 \%$ ) corresponds to the decomposition of quinoline group. Leaving the residue corresponded to stable $\mathrm{CoO} 8.15 \%$ (calcd. $9.17 \%$ ). The TG curve of the $\mathrm{Ni}(\mathrm{II})$ complex shows a three-steps of decomposition. The first step at $35-90{ }^{\circ} \mathrm{C}$ with weight loss of 11.10 (Calcd.12.01\%) is attributed to the loss of the two water molecules, the second step with weight loss of 25.62 (Calcd. $26.29 \%$ ) at $180-265^{\circ} \mathrm{C}$ is corresponding to the removal of corresponding oxazole with carbonyl group from the coordinated ligand. The third step at $280-618^{\circ} \mathrm{C}$ with weight loss of 32.00 (Calcd. $34.81 \%$ ) is referring to the removal of quinoline moiety, and giving the residual part is $\mathrm{NiO} 13.85 \%$ (calcd. $15.37 \%$ ). In the TG curve of $\mathrm{Cu}(\mathrm{II})$ complex, the first step of decomposition from 28 to $75^{\circ} \mathrm{C}$, with a mass loss $11.75 \%$ (calcd. $12.83 \%$ ), ascribed to the removal of the non-coordinated part of the oxazole group. The second step starts from 155 to $340{ }^{\circ} \mathrm{C}$ with mass loss $49.30 \%$ (calcd. $49.10 \%$ ) corresponds the loss of one more part of ligand quinoline moiety, the mass of the final residue corresponded to stable $\mathrm{CuO}, 20.85 \%$ (calcd. $18.37 \%$ ). The results well established with the composition of the metal complexes.

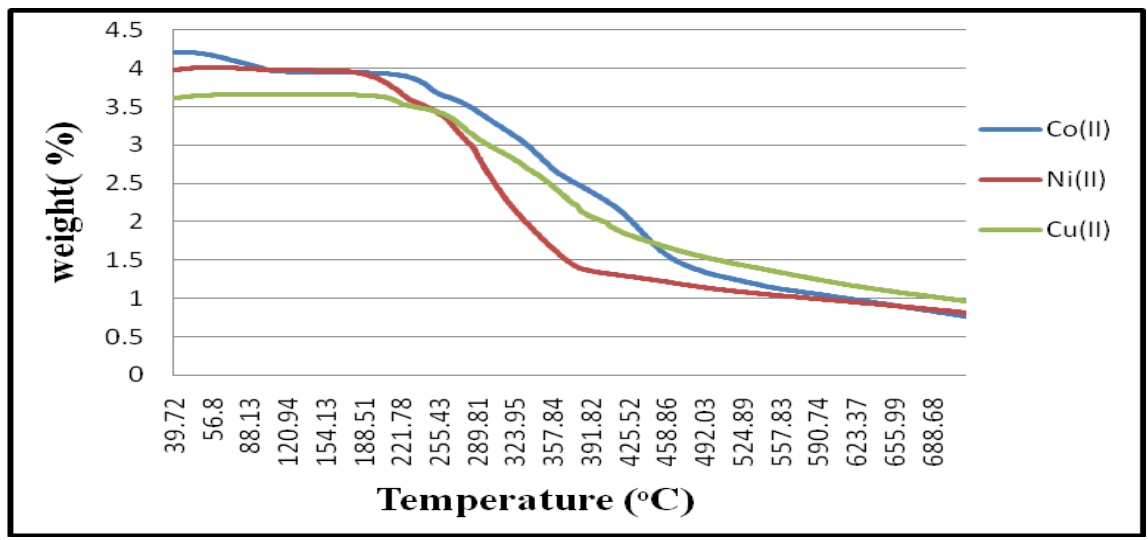

Fig 5. TGA and DTA curves Co (II), Ni(II) and Cu(II) complexes. 
Metal Complexes of quinolin-8-yl (1, 3-benzoxazol-2-ylsulfanyl) acetate: Spectral, XRD, thermal,

\subsection{Antimicrobial activity}

All the synthesized complexes and ligand (BZ) have been examined towards three bacterial and fungal strains the use of agar well diffusion method [30]. All bacterial traces were maintained on nutrient agar medium at $\pm 37{ }^{\circ} \mathrm{C}$, and fungal strains were maintained on potato dextrose agar (PDA) at $\pm 25^{\circ} \mathrm{C}$. The test compounds had been dissolved in DMSO. Sample-loaded plates were inoculated with the micro organism incubated at 37 ${ }^{\circ} \mathrm{C}$ for $24 \mathrm{~h}$, and culture was incubated at $25{ }^{\circ} \mathrm{C}$ for $60 \mathrm{~h}$. DMSO as control and chloramphenicol and fluconazole is used as standards for bactericide and fungicide. (Table 6) All the synthesized complexes and ligand (BZ) showed inhibition property, among them $\mathrm{Ni}(\mathrm{II})$ and $\mathrm{Cu}(\mathrm{II})$ complexes shows excellent when compared to standards. The compounds were also tested for minimal inhibitory concentration (MIC) values [19]. MIC values of less than $25 \mu \mathrm{g} / \mathrm{mL}$ are shown in table 7, it observed that ligand (BI) and Co(II) complex showed least activity, $\mathrm{Ni}(\mathrm{II})$ and $\mathrm{Cu}(\mathrm{II})$ complexes showed promising activity.

Table 4 Antimicrobial datas - Zone inhibition

\begin{tabular}{|c|c|c|c|c|c|c|}
\hline \multirow[b]{2}{*}{ Compounds } & \multicolumn{3}{|c|}{ Antibacterial zone inhibition in $\mathrm{mm}($ mean \pm SD) } & \multicolumn{3}{|c|}{ Antifungal zone inhibition in $\mathrm{mm}($ mean $\pm \mathrm{SD})$} \\
\hline & S. aureus & B. subtilis & E. coli & S. coccus & C. albicans & A. niger \\
\hline Ligand (BZ) & $03 \pm 0.3$ & $05 \pm 0.2$ & $05 \pm 0.7$ & $04 \pm 0.4$ & $03 \pm 0.1$ & - \\
\hline Co(II) & $06 \pm 0.3$ & - & $07 \pm 0.3$ & $08 \pm 0.2$ & - & $06 \pm 0.3$ \\
\hline $\mathbf{N i}($ II $)$ & $14 \pm 0.2$ & $12 \pm 0.4$ & $10 \pm 0.2$ & $10 \pm 0.6$ & $09 \pm 0.2$ & $11 \pm 0.3$ \\
\hline $\mathbf{C u}(\mathbf{I I})$ & $13 \pm 0.1$ & $15 \pm 0.1$ & $12 \pm 0.3$ & $08 \pm 0.4$ & $10 \pm 0.1$ & $10 \pm 0.3$ \\
\hline Chloramphenicol & $15 \pm 0.2$ & $16 \pm 0.3$ & $13 \pm 0.3$ & $12 \pm 0.2$ & $11 \pm 0.4$ & $13 \pm 0.3$ \\
\hline Fluconazole & - & - & - & $12 \pm 0.2$ & $10 \pm 0.1$ & $12 \pm 0.3$ \\
\hline DMSO & 0 & 0 & 0 & 0 & 0 & 0 \\
\hline
\end{tabular}

Table 5. Antimicrobial datas Minimal inhibitory concentration

\begin{tabular}{|c|c|c|c|c|c|c|}
\hline \multirow[b]{2}{*}{ Compounds } & \multicolumn{6}{|c|}{ MIC of the compounds in $25 \mu \mathrm{g} / \mathrm{mL}$} \\
\hline & S. aureus & B. subtilis & E. coli & S. coccus & C. albicans & A. niger \\
\hline Ligand (BZ) & 10 & - & 12 & 09 & 08 & - \\
\hline $\operatorname{Co}($ II $)$ & 11 & 10 & - & 08 & 10 & 11 \\
\hline $\mathrm{Ni}(\mathrm{II})$ & 18 & 21 & 17 & 19 & 21 & 15 \\
\hline $\mathrm{Cu}(\mathrm{II})$ & 19 & 20 & 22 & 17 & 13 & 22 \\
\hline
\end{tabular}

\subsection{Antioxidant activity}

DPPH radical scavenging activity data of the synthesized ligand BZ and their metal complexes exhibited that all the compounds having highly potency activity represented in figure 6 . The metal complexes exhibited more radical scavenging activity than that of the ligand $\mathrm{BZ}$. $\mathrm{Cu}(\mathrm{II})$ metal complex exhibited effective antioxidant activity almost close to the standard BHT and ligand BZ complex showed lower antioxidant activity and $\mathrm{Co}(\mathrm{II}), \mathrm{Ni}(\mathrm{II})$ complexes showed moderate activity when compared with BHT. The activity is due the presence imidazole and Isoniazid nucleus in the coordinated metal ion with ligand BZ [31].

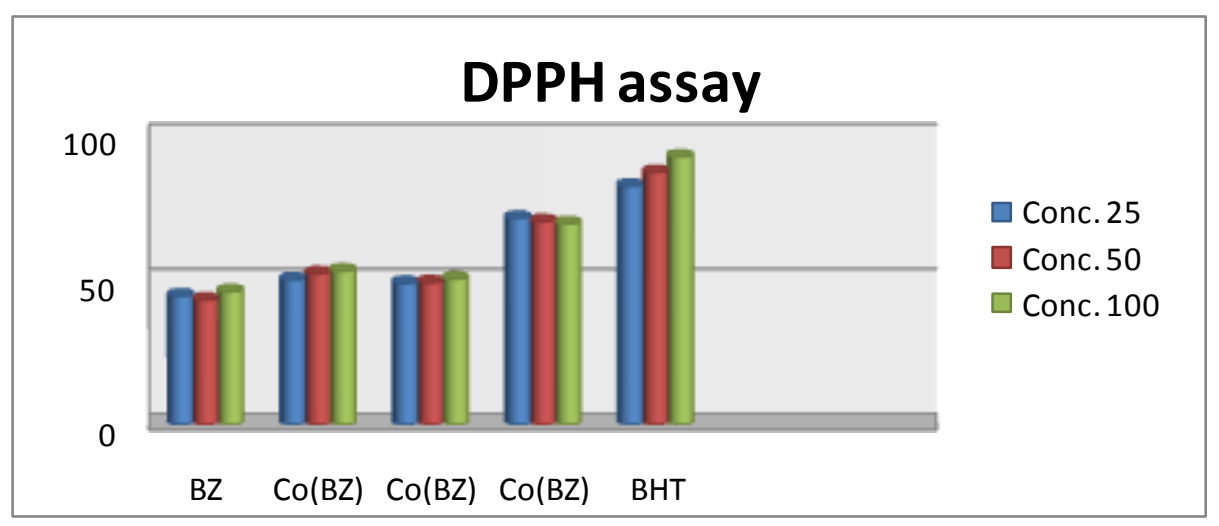

Fig 6. Antioxidant datas of $\mathrm{BZ}$ and metal complexes

\subsection{Molecular docking studies}

In order to interrupt the binding interactions modes In-vitro of BZ and metal complexes with human antioxidant enzyme in complexes with the competitive inhibitor DTT (PDB: 3MNG) [32]. The binding energy all the complexes showed prominent binding interactions, $\mathrm{Co}$ (II) exhibits the $-330.54 \mathrm{Kcal} / \mathrm{mol}$, while $\mathrm{Ni}(\mathrm{II})$ 
complexes shows $-335.21 \mathrm{Kcal} / \mathrm{mol}$ and $\mathrm{Cu}(\mathrm{II})$ complex gives highest binding energy of $-354.58 \mathrm{Kcal} / \mathrm{mol}$ with human antioxidant $3 M N G$ protein receptor by the key of amino acids LEU-97, VAL-69, ALA-71, CYS-72, PHE-37. Hydrophobic and hydrophilic spheres are used to recognize the interactive positions which will be the potential ligand binding sites in each possible position. Finally, the molecular docking studies for the selected compounds revealed that the synthesized compounds are antioxidant competitive inhibitors in comparison to antioxidant inhibitor DTT at 3MNG binding receptor.
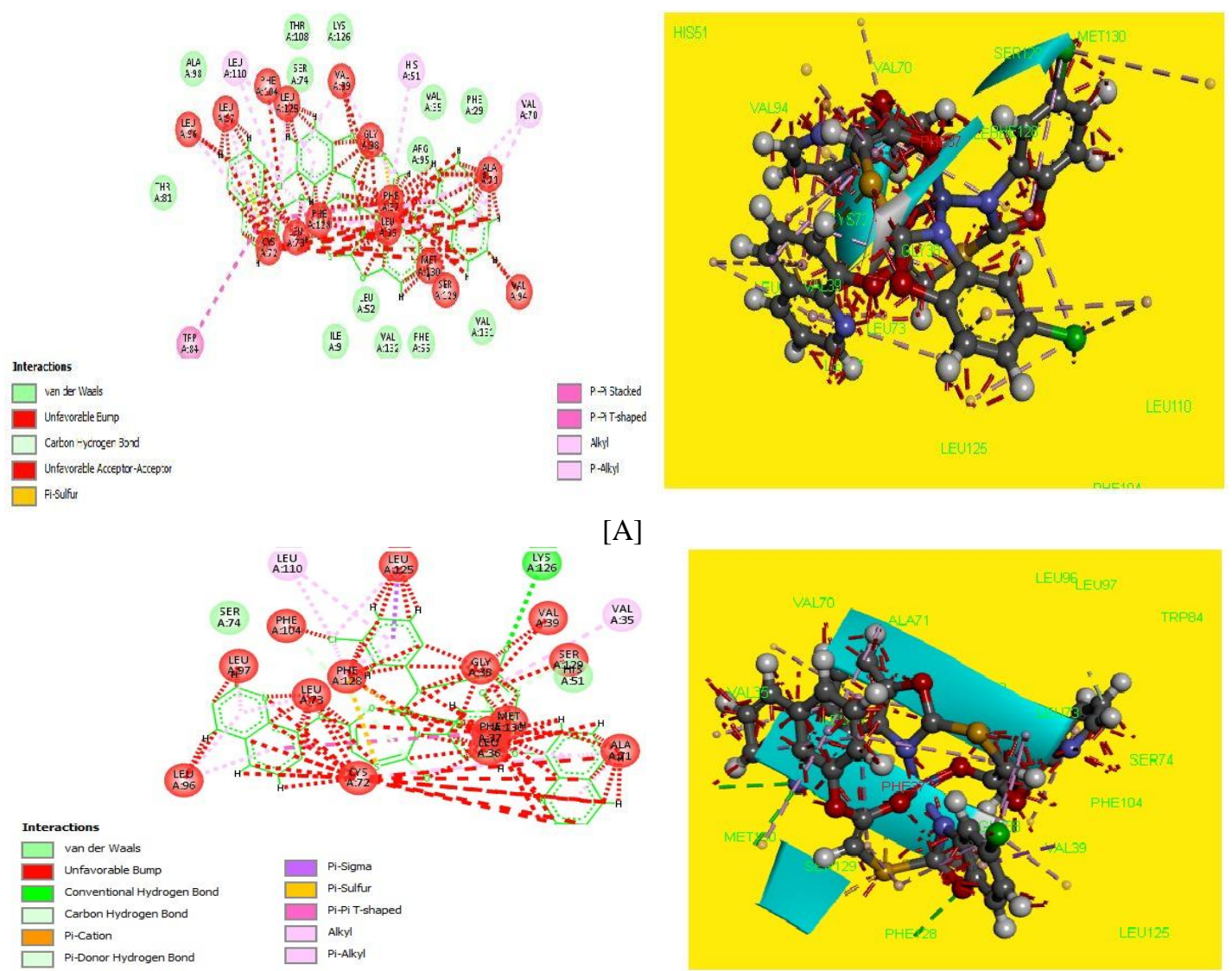

$[\mathrm{B}]$
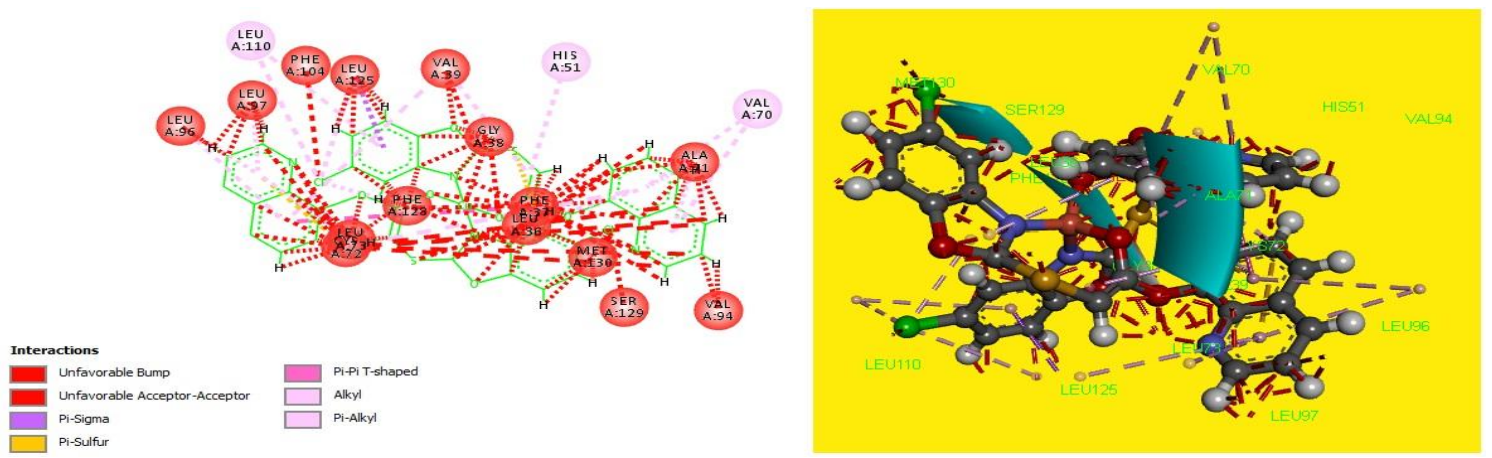

$[\mathrm{C}]$

Fig 7. Binding interaction of [A] $\mathrm{Co}(\mathrm{II}),[\mathrm{B}] \mathrm{Ni}(\mathrm{II})$ and $[\mathrm{C}] \mathrm{Cu}(\mathrm{II})$ complexes with $3 \mathrm{MNG}$ receptor

\section{Conclusion}

The $\mathrm{Co}$ (II), Ni(II) and $\mathrm{Cu}$ (II) complexes with benzoxazole derived ligand quinolin-8-yl (1,3-benzoxazol-2ylsulfanyl)acetate (BZ) were synthesized and characterized. The Uv-visible and IR data showed that the complexes are tridentate in nature, by bonding with carbonyl oxygen and nitrogen of oxazoles group to the metal atom. The thermal stability of the complexes are performed and the powder XRD patterns of $\mathrm{Ni}$ (II) and $\mathrm{Cu}$ (II) complexes showed nanocrystalline in nature. The antioxidant activity of compounds showed that promising scavenging inhibition in DPPH and it is correlated with human antioxidant enzyme in complexes with the competitive inhibitor DTT (PDB: 3MNG), which gives good binding interactions between complexes and receptor. From antimicrobial results, all the complexes and uncoordinated ligand exhibits excellent zone inhibition towards bacterial and fungal strains. 


\section{References}

[1] M. Prudhomme, J. Guyot, G. Jeminet, Semi-synthesis of A23187 (calcimycin) analogs. IV. Cation carrier properties in mitochondria of analogs with modified benzoxazole rings Antimicrobial activity, Journal of Antibiotics. 39, (1986), 934-7.

[2] D.D. Martin, N.R. Kotecha, S.V. Ley, S. Maqntegani, J.C. Menendes, H.M White, Total synthesis of the ionophore antibiotic CP61,405 (routiennocin), Tetrahedron 48 (37), (1992), 7899.

[3] I. Yildiz-Oren, I. Yalcin, E. Aki-Sener, N. Ucarturk, Synthesis and structure-activity relationships of new antimicrobial active multisubstituted benzazole derivatives, European Journal Medicinal Chemistry, 39 (2004) 291-298.

[4] G. Turan-Zitoni, S. Demirayak, A. Ozdemir, Z.A. Kaplancıkl1, M.T. Yildiz, Synthesis of some 2-[(benzazole-2yl)thioacetylamino]thiazole derivatives and their antimicrobial activity and toxicity. European Journal Medicinal Chemistry, 39(3), (2004), 267-72.

[5] J. Vinsova, V. Horak, V. Buchta, J. Kaustova, Highly Lipophilic Benzoxazoles with Potential Antibacterial Activity, Molecules 10, (2005), 783 .

[6] M.B. Reynolds, M.R. DeLuca, S.M. Kerwin, The novel bis(Benzoxazole) cytotoxic natural product UK-1 is a magnesium iondependent DNA binding agent and inhibitor of human topoisomerase II, Bioorganic Chemistry, 27, (1999), 326.

[7] I. Yildiz-Oren, I. Yalcin, E. Aki-Sener, N. Ucarturk, Synthesis and structure-activity relationships of new antimicrobial active multisubstituted benzazole derivatives, European Journal Medicinal Chemistry, 39 (2004) 291-298.

[8] B.B. Wang, N. Maghami, V.L. Goodlin, P.J. Smith, Synthesis, Metal Ion Binding, and Biological Evaluation of New Anticancer 2(2'-Hydroxyphenyl)benzoxazole Analogs of UK-1, Bioorganic Chemistry, 16(4), (2008), 1775-83.

[9] S.T. Huang, I.J. Hsei, C. Chen, Synthesis and anticancer evaluation of bis(benzimidazoles), bis(benzoxazoles), and benzothiazoles, Bioorganic Medicinal Chemistry, 14, (2006), 6106.

[10] O. Temiz-Arpac1, I. Yıldız, S. Ozkan, F. Kaynak, Synthesis and biological activity of some new benzoxazoles, European Journal Medicinal Chemistry. 43(7), (2008), 1423-31.

[11] S. Djebbar-Sid, O. Benali-Baitich, J.P. Deloume, Synthesis, characterization, electrochemical behaviour and catalytic activity of manganese(II) complexes with linear and tripodal tetradentate ligands derived from Schiff bases, Transition Metal. Chemistry, 23(4) (1998), 443-447.

[12] F.S. Rodembusch, F.R. Brand, D.S. Correa, J.C. Pocos, M. Martinelli, Transition metal complexes from 2-(2'hydroxyphenyl)benzoxazole: A spectroscopic and thermogravimetric stability study, Materials Chemistry and Physics, 92, (15), (2005), 389-393

[13] B. Tekiner-Gulbas, O. Temiz-Arpaci, I. Yildiz, N. Altanlar, Synthesis and in vitro antimicrobial activity of new 2-[p-substitutedbenzyl]-5-[substituted-carbonylamino]benzoxazoles. European Journal Medicinal Chemistry, 42(10), (2007), 1293-9.

[14] O. Temiz-Arpac, B. Tekiner-Gulbas, I. Yildiz, E. Aki-Sener, I. Yalcin, 3D-QSAR analysis on benzazole derivatives as eukaryotic topoisomerase II inhibitors by using comparative molecular field analysis method. 13(23), (2005), 6354.

[15] J. Jiang, X. Tang, W. Dou, H. Zhang, W. Liu, C. Wang, J. Zheng, Synthesis and characterization of the ligand based on benzoxazole and its transition metal complexes: DNA-binding and antitumor activity Journal of inorganic biochemistry,48, (2010), 583.

[16] S.M. Rida, F.A. Ashour, S. El-Hawash, M. El-Semary, M.H. Badr, M.A. Shalaby, Synthesis of some novel benzoxazole derivatives as anticancer, anti-HIV-1 and antimicrobial agents, European Journal Medicinal Chemistry, 40 (9), (2005), 949.

[17] M. Zhang, R. Gao, X. Hao, W.H. Sun, 2-Oxazoline/benzoxazole-1,10-phenanthrolinylmetal (iron, cobalt or nickel) dichloride: Synthesis, characterization and their catalytic reactivity for the ethylene oligomerization, Journal of Organometallic Chemistry,693, (2008), 3867.

[18] Y. Harinath, D. Subba rao, C. Suresh, K. Seshaiah, Synthesis, characterization and studies on antioxidant and molecular docking of metal complexes of 1-(benzo[d]thiazol-2-yl)thiourea, Journal of Chemical Sciences. 128, (2016), 43-51.

[19] N.D .Shashikumar, G. Krishnamurthy, H.S. Bhojya Naik, M.R. Lokesh and K. S. Jithendra kumara, Synthesis of new biphenylsubstituted quinoline derivatives, preliminary screening and docking studies, Journal of chemical sciences, 126(1), (2014), $205-212$.

[20] A. Hall, D. Parsonage, L.B. Poole, P.A Karplus, Structural evidence that peroxiredoxin catalytic power is based on transition-state stabilization. Journal of Molecular Biology. 402(1), (2010), 194-209.

[21] MA. Abdel Nasser, A. Alaghaz, Badr, A. El-Sayed. Ahmed, El-Henawy, A.A. Reda, Ammar. Synthesis, spectroscopic characterization, potentiometric studies, cytotoxic studies and molecular docking studies of DNA binding of transition metal complexes with 1,1-diaminopropane-Schiff base, Journal of Molecular Structure. (1035), (2013), 83-93.

[22] Nakamoto K. Infrared and Raman Spectra of Inorganic and Coordination Compounds. In:Chalmers JM, Griffiths PR, editors. Handbook of vibrational spectroscopy, Chichester, (UK: John Wiley \& Sons, Ltd; 2006).

[23] Sangeetha Gowda K.R, Bhojya Naik H.S, Vinay Kuma B, Sudhamani C.N, Sudeep H.V, Ravikumar Naik T.R, Krishnamurthy G. Synthesis, antimicrobial, DNA-binding and photonuclease studies of Cobalt(III) and Nickel(II) Schiff base complexes. Spectrochimica Acta Part A: Mol and Biomol Spect (105), (2013), 229-237.

[24] Abdel Nasser MA, Alaghaz, Badr A, El-Sayed. Ahmed A, El-Henawy, Reda AA, Ammar. Synthesis, spectroscopic characterization, potentiometric studies, cytotoxic studies and molecular docking studies of DNA binding of transition metal complexes with 1,1-diaminopropane-Schiff base. Journal of Molecular Structure, (1035), (2013), 83-93.

[25] Sreekanth B, Krishnamurthy G, Bhojya Naik H. S, Vishnuvardhan T. K. CU(II) and MN(II) complexes containing macroacyclic ligand: Synthesis, DNA binding, and cleavage studies. Nucleosides, Nucleotides and Nucleic Acids, (8), (2012), $311-13$.

[26] Ashraf A, Siddiqui W.A, Akbar J, Mustafa G, Krautscheid H, Ullah N. Metal complexes of benzimidazole derived sulfonamide: Synthesis, molecular structures and antimicrobial activity. Inorganic Chimca Acta. (443), (2016), 179-85.

[27] G. Krishnamurthy, Shashikala N. Synthesis of ruthenium(II) carbonyl complexes with 2-monosubstituted and 1,2-disubstituted benzimidazoles, Journal of Serbian Chemical Society, 74 (10), (2009), 1085-1096.

[28] Lever A.B.P. Inorganic electronic spectroscopy. 2nd ed. (Amsterdam; New York: Elsevier; 1984).

[29] Mustafa B, Gokhan C, Baris A, Muhammet K, Ahmet K, Mukerrem K. Synthesis and X-ray powder diffraction, electrochemical, and genotoxic properties of a new azo-Schiff base and its metal complexes, Turkish journal of chemistry, (38), (2014), 22-241.

[30] Declercq J P, Evrard C, Clippe A, Stricht D V, Bernard A, Knoops B. Crystal structures of human peroxiredoxin 5, novel type of mammalian peroxiredoxin at 1.5 A resolution, Journal of Molecular Biology. (4) 311, (2001), 751-9.

[31] Rajesh M.P, Natvar J.P, In vitro antioxidant activity of coumarin compounds. Journal of Advanced Pharmacy Education \& Research, (1), (2011) 52-68.

[32] Y. Harinath, D. Subba rao, C. Suresh, K. Seshaiah, Synthesis, characterization and studies on antioxidant and molecular docking of metal complexes of 1-(benzo[d]thiazol-2-yl)thiourea, Journal of Chemical Sciences. 128, (2016), 43-51. 